\title{
Spectrophotometric Methods for Determination of Tranexamic Acid and Etamsylate in Pure Form and Pharmaceutical Formulation
}

\author{
Gehad G. Mohamed, Eman Y.Z. Frag and Abeer A. Sedeek \\ Department of Chemistry, Faculty of Science, Cairo University, Giza, Egypt
}

\begin{abstract}
Background: Tranexamic acid and etamsylate drugs belong to a group of antifibrinolytics. Tranexamic Acid (TRA) is the most potent antifibrinolytic lysine analogue used in a broad spectrum of peri-and postoperative interventions and bleeding disorders. The administration of TRA is associated with a reduction in bleeding due to its inhibitory effect on clot breakdown (fibrinolysis). Etamsylate (ESL) is a haemostatic agent that appears to maintain the stability of the capillary wall and correct abnormal platelet adhesion. It is given for the prophylaxis and control of haemorrhages from small blood vessels. Objective: Two simple and sensitive spectrophotometric methods are described for the determination of tranexamic acid (TRA) and etamsylate (ESL) drugs in pure form and pharmaceutical preparations. Materials and Methods Method (A) is used for the determination of TRA and based on condensation reaction of the primary amino group of TRA with salicylaldehyde reagent (SA) (Schiff base formation) producing a yellow coloured product which is measured spectrophotometrically at $400 \mathrm{~nm}$. Method (B) is utilized for the determination of ESL and based on the oxidation-reduction reaction of ESL using iodic acid $\left(\mathrm{HIO}_{3}\right)$. The liberated iodine was extracted in chloroform and the absorbance of the red coloured product is measured spectrophotometrically at $510 \mathrm{~nm}$. For method A and B, different variables affecting the reactions were studied and optimized. Results: Under the optimum conditions, linear relationships with good correlation coefficients 0.9989 and 0.9959 were found between the absorbance and the concentration of the drug in the range from 5 to 500 and 2.5 to $275 \mu \mathrm{g} \mathrm{mL}^{-1}$ for ESL and TRA drugs, respectively. The limit of detection $\left(\mu \mathrm{g} \mathrm{mL} L^{-1}\right)$, limit of quantification $\left(\mu \mathrm{g} \mathrm{mL}^{-1}\right)$ and molar absorptivity $\left(\mathrm{L} \mathrm{mol}^{-1} \mathrm{~cm}^{-1}\right)$ values were found to be $1.442,4.80$ and $5.39 \times 10^{2}$ for TRA drug and 2.20, 7.25 and $3.0 \times 10^{2}$ for ESL drug, respectively. Conclusion: The method was applied for determination of the investigated drugs in tablets. The method was validated and can be suggested for routine analysis of both drugs.
\end{abstract}

Key words: Etamsylate, tranexamic acid, salicylaldehyde, Schiff base reaction, oxidation-reduction reaction, iodic acid

Insight Pharmaceutical Sciences 5 (1): 1-7, 2015

\section{INTRODUCTION}

Tranexamic acid and etamsylate drugs belong to a group of antifibrinolytics. Tranexamic acid [trans-4(aminomethyl) cyclohexane carboxylic acid] (TRA) is the most potent antifibrinolytic lysine analogue (Fig. 1a) used in a broad spectrum of peri-and postoperative interventions and bleeding disorders ${ }^{1,2}$. The administration of TRA is associated with a reduction in bleeding due to its inhibitory effect on clot breakdown (fibrinolysis). Etamsylate (ESL), chemically known as 2,5-dihydroxybenzene sulphonic acid with ethylene diamine. Etamsylate (Fig. 1b) is a haemostatic agent that appears to maintain the stability of the capillary wall and

$\overline{\text { Corresponding Author: Gehad Genidy Mohamed, Department of }}$ Chemistry, Faculty of Science, Cairo University, Giza, Egypt Tel: +2-0129160411, +2-02-35676896 correct abnormal platelet adhesion. It is given for the prophylaxis and control of haemorrhages from small blood vessels ${ }^{3}$.<smiles>NCC1CCC(C(=O)O)CC1</smiles><smiles>CCNCC</smiles>

Fig. 1(a-b): Structures of (a) Tranexamic acid and (b) Etamsylate drugs 
Several methods have been reported for the determination of ESL drug in pharmaceutical dosage forms and in biological fluids including high-performance liquid chromatography ${ }^{4-6}$, high-performance thin layer chromatography ${ }^{7,8}$, flow injection potentiometry ${ }^{9}$, chemiluminescence methods ${ }^{10-12}$, UV spectrophotometry ${ }^{13,14}$ and titrimetric method $^{15}$. The methods of determination of TRA drug in pharmaceutical dosage forms and in biological fluids are high-performance Liquid Chromatography (LC) ${ }^{16-18}$, high-performance liquid chromatography-fluorescence $\operatorname{method}^{19}$, spectrophotometric methods ${ }^{20-22}$ and flow-injection methods ${ }^{23}$.

This study describes the oxidation-reduction and condensation reactions for the spectrophotometric determination of ESL and TRA drugs, respectively. Different experimental conditions were optimized and Beer's law is carried out. The methods are successfully applied for the determination of ESL and TRA drugs in tablets.

\section{MATERIALS AND METHODS}

Reagents: All reagents and chemicals used were of analytical grade and all solutions were freshly prepared daily. The TRA and ESL drugs were supplied from the National Organization for Drug Control and Research, Egypt. Salicylaldehyde (SA) and iodic acid $\left(\mathrm{IO}_{3}\right)$ reagents were supplied from Riedel-deHaen and B.D.H, respectively. Absolute ethanol (supplied from Adwic) and all solvents used throughout this study were of analytical grade including methylene chloride, chloroform and petroleum ether (supplied from El-Nasr Company).

Procedure for stock solution preparation: Standard solutions of ESL drug $\left(3.79 \times 10^{-3} \mathrm{~mol} \mathrm{~L}^{-1}\right)$ were prepared by dissolving an accurately weighed quantity of drug in a definite volume of methanol. Standard solutions of TRA drug $\left(6.4 \times 10^{-3} \mathrm{~mol} \mathrm{~L}^{-1}\right)$ were prepared by dissolving an accurately weighed quantity of it in bidistilled water and completed by absolute ethanol in the percent 1:2.33 $\left(\mathrm{H}_{2} \mathrm{O} /\right.$ absolute ethanol) ratio. About $10 \mathrm{mg} \mathrm{mL}^{-1}$ of salicylaldehyde reagent was prepared in absolute ethanol and $20 \mathrm{mg} \mathrm{mL}^{-1}$ of iodic acid $\left(\mathrm{HIO}_{3}\right)$ was prepared in bidistilled water. Tablets containing etamsylate (Haemostop, $250 \mathrm{mg} /$ tablet) and tranexamic acid (Kapron, $500 \mathrm{mg} /$ tablet) were supplied from Amoun Pharmaceutical Company, Egypt.

Apparatus: All absorbance measurements were carried out using the manual Unico 1200 (United Products and
Instruments, Inc., Germany) in the wavelength range from 325-1000 nm. Small volumes were taken using micropipette.

\section{General procedure \\ Batch measurements}

Method A: In calibrated $5 \mathrm{~mL}$ volumetric flask, different aliquots containing 2.50-275.0 $\mu \mathrm{g} \mathrm{mL}^{-1}$ of TRA was added to $1 \mathrm{~mL}$ of $1 \%(\mathrm{w} / \mathrm{v})$ salicylaldehyde solution (SA). The volume was completed to the mark with absolute ethanol. The complete colour development was attained after $45 \mathrm{~min}$. Then, the absorption spectra of the resulted Schiff base product was measured at $\lambda=400 \mathrm{~nm}$ against SA reagent blank.

Method B: Aliquots containing ESL drug (5-500 $\mu \mathrm{g} \mathrm{mL}^{-1}$ ) was added to $1 \mathrm{~mL}$ of $2 \%$ (w/v) $\mathrm{HIO}_{3}$ and the mixture was completed to $10 \mathrm{~mL}$ by bidistilled water. After $30 \mathrm{~min}, 5 \mathrm{~mL}$ chloroform was added and shaked well for $1 \mathrm{~min}$. Complete extraction of the liberated iodine was done and the chloroform layer was separated and collected in $10 \mathrm{~mL}$ measuring flask. The absorbance of the colored product was measured at $\lambda=510 \mathrm{~nm}$ against chloroform as a blank.

In both spectrophotometric methods (A and $\mathrm{B}$ ), a calibration curve was prepared by plotting the absorbance values, increasing absorbance values versus concentration of TRA and ESL drugs $\left(\mu \mathrm{g} \mathrm{mL}^{-1}\right)$. The concentration of TRA and ESL drugs in drug formulations was calculated from the equations of the calibration graph.

\section{RESULTS AND DISCUSSION}

Spectral characteristics: Figure 2 shows the absorption spectra of TRA and ESL. The TRA drug condenses with salicylaldehyde giving a yellow Schiff base product of stable yellow colour exhibiting maximum wavelength at $400 \mathrm{~nm}$ and the reaction proceeds in ethanol (Fig. 2a). TRA drug contains a primary amine which reacts with an active carbonyl group in salicylaldehyde forming Schiff bases, compounds containing an azomethine group $(-\mathrm{RCH}=\mathrm{N}-)$. The proposed structure is shown in Fig. 3.

The ESL drug reacts with $\mathrm{HIO}_{3}$, an oxidation-reduction reaction occurs with the liberation of iodine. The liberated iodine is extracted in chloroform and the absorbance was measured in the wavelength $=510 \mathrm{~nm}$ (Fig. 2b). The mechanism of oxidation of ESL drug is given in Fig. 4. 

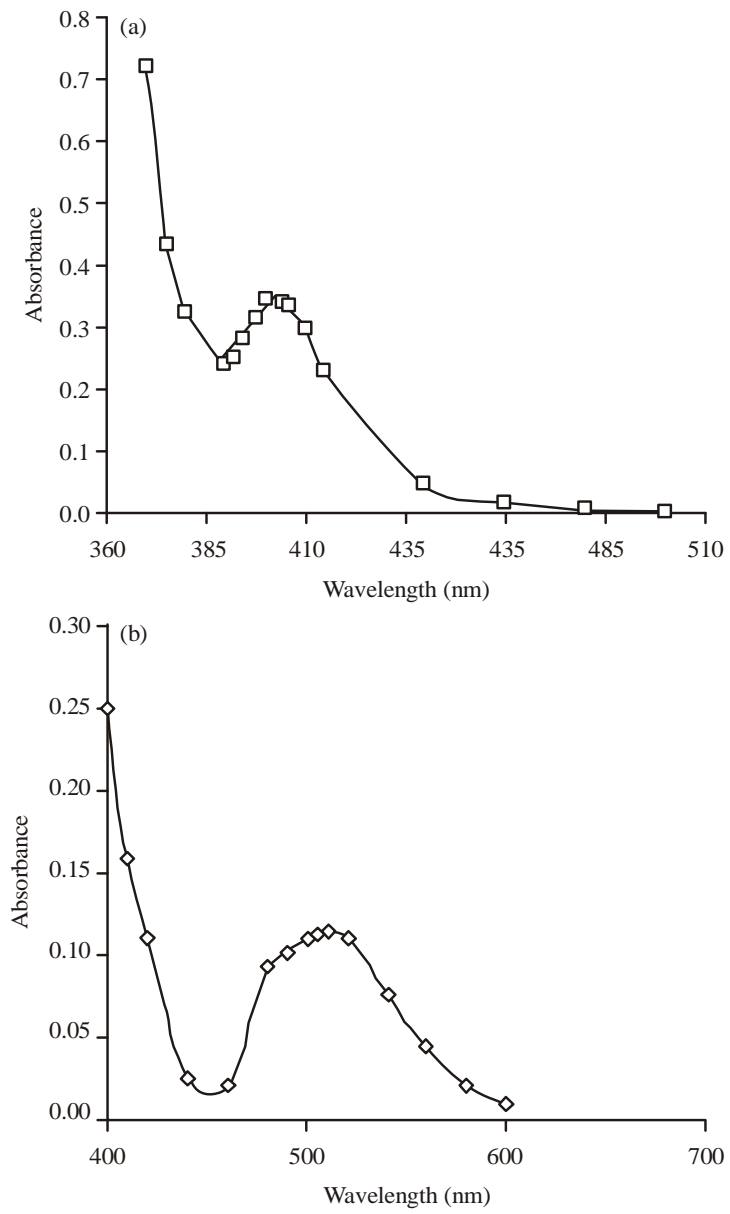

Fig. 2(a-b): Absorption spectra of (a) TRA drug condenses with salicylaldehyde in ethanol (b) ESL oxidation-product resulted from its reaction with $\mathrm{IO}_{3}{ }^{-}$in ethanol<smiles>NCC1CCC(C(=O)O)CC1</smiles><smiles>O=C(O)C1CCC(CN=Cc2ccccc2O)CC1</smiles>

Fig. 3: Reaction of tranexamic acid with salicylaldehyde forming Schiff base

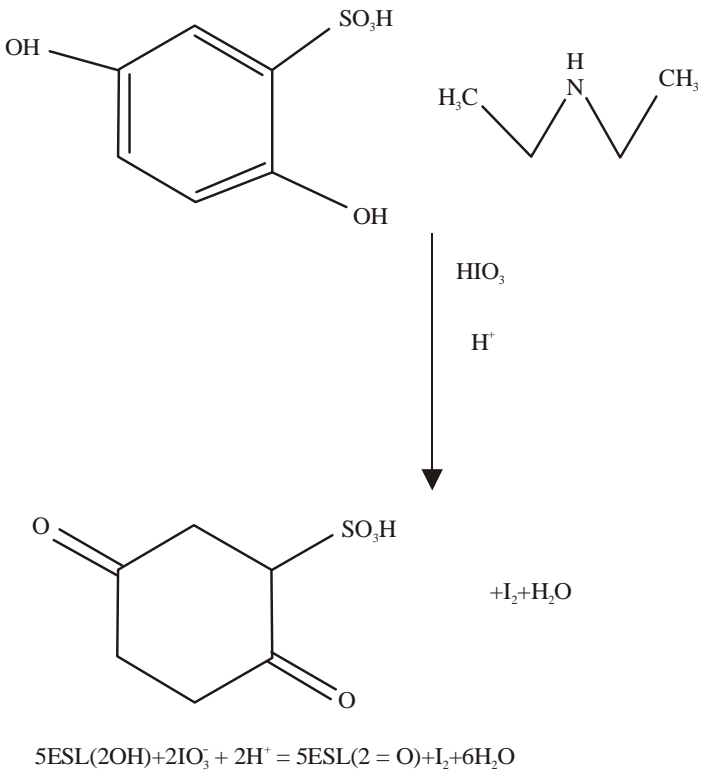

Fig. 4: Mechanism of oxidation reduction reaction between periodic acid and ESL drug

\section{Optimization of reaction conditions}

Effect of reagent concentration: The ESL and TRA drugs under investigation $\left(100 \mu \mathrm{g} \mathrm{mL}^{-1}\right)$ are allowed to react with varying volumes of $\mathrm{HIO}_{3}$ and salicylaldehyde, respectively. The maximum absorbance is obtained with 0.3 and $0.4 \mathrm{mg} \mathrm{mL}^{-1}$ of $\mathrm{HIO}_{3}$ and salicylaldehyde, respectively. Higher concentrations of the reagents have no effect that may be useful for rapidly reaching equilibrium, thus minimizing the time required for attaining maximum absorbance at the corresponding wavelengths.

Effect of solvents: The reaction of ESL drug under investigation with $\mathrm{HIO}_{3}$ reagent is made in different solvents. Chloroform shows high absorbance over petroleum ether and methylene chloride (Fig. 5), hence, it was chosen as an extraction solvent for the subsequent steps.

Effect of reaction time and temperature: For TRA drug, the effect of temperature $\left(0-90^{\circ} \mathrm{C}\right)$ and time on the condensation reaction is optimized. The results obtained indicate that, complete colour development is attained immediately at $40^{\circ} \mathrm{C}$ after $45 \mathrm{~min}$ (Fig. 6). The absorbance of the reaction products is increased with the increase of temperature up to $40^{\circ} \mathrm{C}$.

For ESL drug, the effect of temperature $\left(0-60^{\circ} \mathrm{C}\right)$ and time on the reaction is optimized. The results obtained indicate that, complete colour development is 


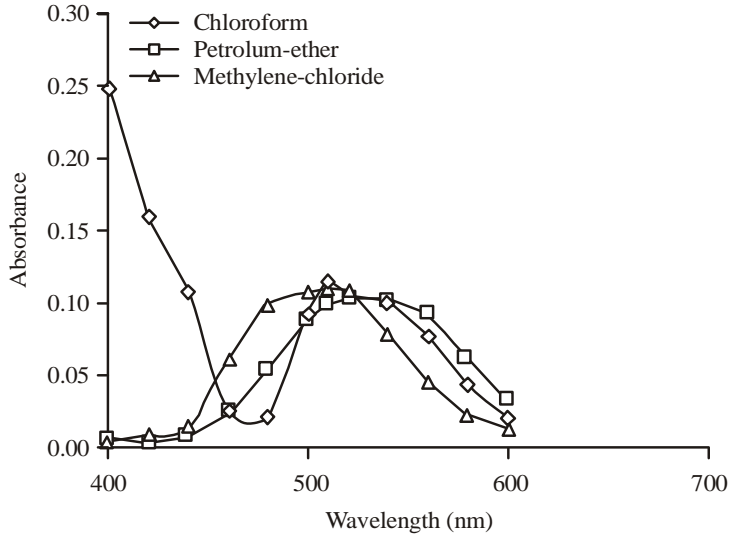

Fig. 5: Effect of solvents in the reaction of ESL oxidation-product resulted from its reaction with $\mathrm{IO}_{3}^{-}$in chloroform
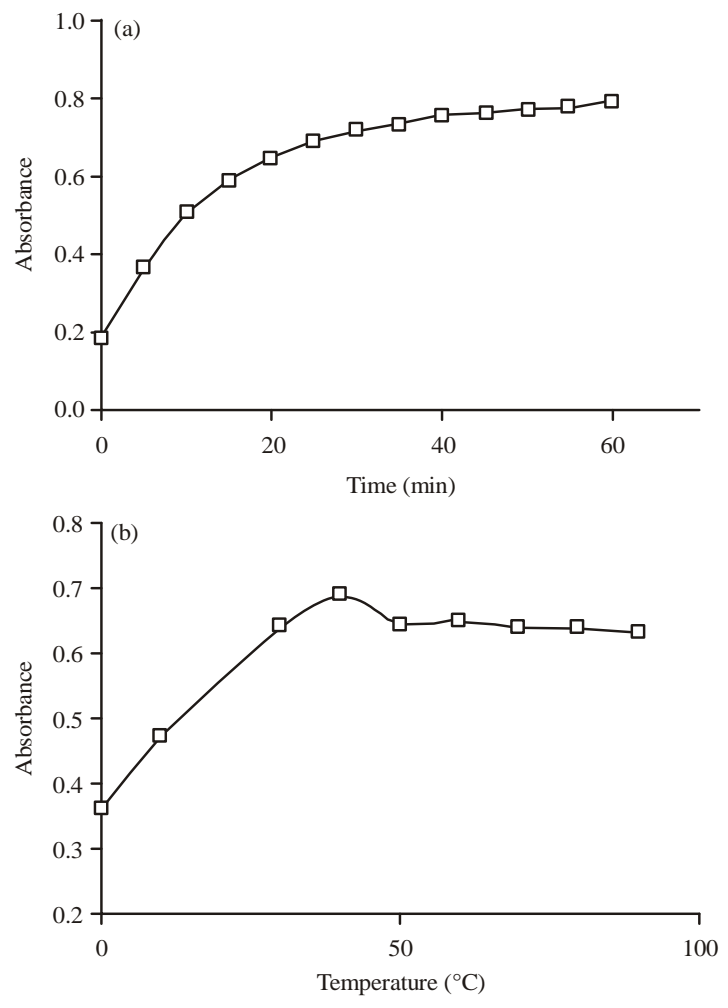

Fig. 6(a-b): Effect of (a) Time and (b) Temperature in the reaction between TRA drug and SA reagent in ethanol

attained immediately at $25^{\circ} \mathrm{C}$ and $30 \mathrm{~min}$ time interval (Fig. 7). The absorbance of the reaction products is increased with the increase of temperature up to $30^{\circ} \mathrm{C}$. Higher temperatures are avoided in quantitative
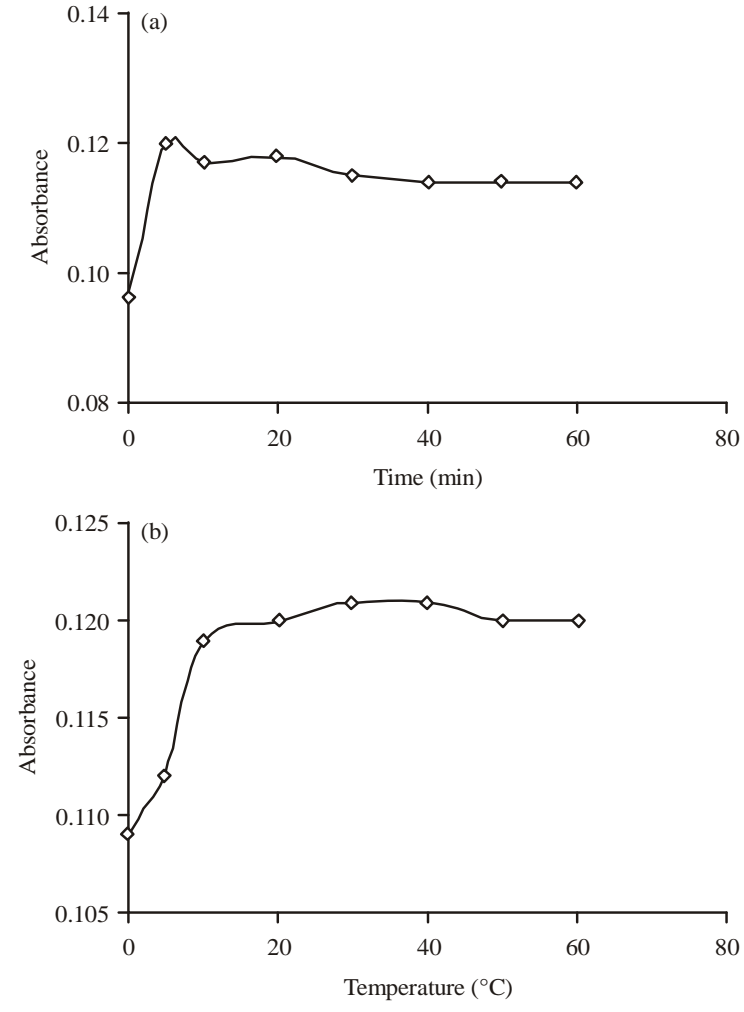

Fig. 7(a-b): Effect of (a) Time and (b) Temperature in the reaction between ESL and $\mathrm{IO}_{3}^{-}$in chloroform

determination of the drug under investigation in their reaction with $\mathrm{HIO}_{3}$ due to the loss of iodine at high temperature.

Validity of Beer's law: Under the optimum conditions described above, the calibration graphs are constructed for the investigated TRA and ESL drugs applying SA and $\mathrm{HIO}_{3}$ reagents, respectively. The molar absorptivities, standard deviations, concentration ranges, regression equations, limits of detection and quantification for each drug using specified reagent is tabulated in Table 1. Beer's law is valid over the concentration range from 5-500 and 2.5 to $275 \mu \mathrm{g} \mathrm{mL}^{-1}$ of ESL and TRA drugs using $\mathrm{HIO}_{3}$ and SA reagents, respectively.

Between-day determination of ESL and TRA drugs: The between day availability of the proposed method is given in Table 2 and shows the values of the between-day relative standard deviations for different concentrations of the drugs, obtained from experiments carried out over a period of four days. It gives a SD of 0.014-0.08 and 0.03-0.09 for ESL and TRA drugs, 
respectively and $\mathrm{RSD} \%$ of 2.83-4.97 and 0.93-3.79 for ESL and TRA drugs, respectively, referring to the high accuracy and precision of the applied procedures.

Spectrophotometric determination of ESL and TRA drugs in pharmaceutical preparations: The results obtained are given in Table 3 . The data show that, the determined concentrations of the ESL and TRA drugs by the proposed methods are closed to that calculated from the official titrimetric methods. In order to check the confidence and correlation between the

Table 1: Spectral characteristics of reaction between ESL and TRA drugs using $\mathrm{HIO}_{3}$ and SA reagents, respectively and the analytical statistics (accuracy and precision) of these reactions

\begin{tabular}{lll}
\hline & Drug & \\
Parameters & ESL & TRA \\
\hline$\lambda_{\max }(\mathrm{nm})$ & 510 & 400 \\
Drug $\left(\mu \mathrm{g} \mathrm{mL}^{-1}\right)$ & $5-500$ & $2.5-275$ \\
$\mathrm{e}\left(\mathrm{L} \mathrm{mol}^{-1} \mathrm{~cm}^{-1}\right)$ & $3.0 \times 10^{3}$ & $5.39 \times 10^{2}$ \\
$\mathrm{~S}\left(\mu \mathrm{g} \mathrm{cm}^{-2}\right)$ & 0.0126 & 0.0118 \\
$\mathbf{A}=\mathbf{m C}+\mathbf{z}$ & & \\
$\mathrm{m}$ & 0.0012 & 0.0072 \\
$\mathrm{z}$ & 0.0101 & 0.0277 \\
$\mathrm{r}^{2}$ & 0.9959 & 0.9989 \\
Recovery $(\%)$ & $98.70-104$ & $99.1-102.0$ \\
LOD $\left(\mu \mathrm{g} \mathrm{mL} \mathrm{mL}^{-1}\right)$ & 2.20 & 1.442 \\
LOQ $(\mu \mathrm{g} \mathrm{mL})$ & 7.25 & 4.80 \\
$\mathrm{SD}$ & $0.005-0.042$ & $0.03-0.082$ \\
RSD $(\%)$ & $1.17-2.64$ & $0.93-2.40$ \\
\hline$\star A=z+\mathrm{mC}^{-1}$; where, C is the concentration in $\mu \mathrm{g} \mathrm{mL}^{-1}$, RSD: Relative \\
standard deviation, SD: Standard deviation
\end{tabular}

Table 2: Between-day precision of the determination of ESL and TRA drugs using $\mathrm{HIO}_{3}$ and $\mathrm{SA}$ reagents

\begin{tabular}{lcccll}
\hline Drug & $\begin{array}{l}\text { Drug taken } \\
\left(\mu \mathrm{g} \mathrm{mL}^{-1}\right)\end{array}$ & $\begin{array}{c}\text { Drug found } \\
\left(\mu \mathrm{gL}^{-1}\right)\end{array}$ & $\begin{array}{l}\text { Percentage } \\
\text { recovery }(\%)\end{array}$ & $\mathrm{SD}^{\star}$ & $\mathrm{RSD}^{\star}$ \\
\hline ESL & 20 & 19.85 & 99.25 & 0.06 & 1.97 \\
& 50 & 52.00 & 104.00 & 0.014 & 4.97 \\
& 200 & 202.00 & 101.00 & 0.05 & 3.61 \\
& 400 & 395.00 & 98.75 & 0.08 & 2.83 \\
TRA & 10 & 9.91 & 99.10 & 0.03 & 3.76 \\
& 50 & 51.00 & 102.00 & 0.05 & 3.79 \\
& 150 & 150.20 & 100.10 & 0.07 & 0.93 \\
& 250 & 249.80 & 99.92 & 0.09 & 1.23 \\
\hline
\end{tabular}

^Average of four replicates suggested spectrophotometric procedures and the official method for determination of ESL and TRA drugs, the percent recovery for all the results are calculated. The percentage recovery values obtained by the proposed methods $\left(\mu \mathrm{g} \mathrm{mL}^{-1}\right)$ are higher than or close to those obtained by the official titrimetric methods $\left(\mathrm{mg} \mathrm{mL}^{-1}\right)$. In addition, the standard deviation values obtained by the proposed methods are close to those obtained by the official titrimetric methods. The small values of standard deviation and relative standard deviation indicate the reliability, accuracy and precision of the suggested procedures.

\section{Method validation}

Linearity: Under optimum experimental conditions for determination of TRA and ESL drugs under investigation, the absorbance versus concentration plots were found to be linear over the concentration ranges stated in Table 1. The regression parameters calculated from the calibration graphs data, along with the standard deviations of the slope (b) and the intercept (a) are presented in Table 1. The linearity of the calibration graphs was demonstrated by the high values of the correlation coefficient (r) and the small values of the intercepts of the regression equations ${ }^{24}$. The molar absorptivity and Sandell sensitivity are also shown in Table 1.

Accuracy and precision: In order to determine the precision of the proposed method, the results of the assay of the studied drug in pharmaceutical preparation were compared with the reference method. Data shown in Table 3 showed no significant differences between them regarding accuracy and precision. Intra-and inter-day precisions were assessed using four concentrations of TRA and ESL were prepared and analyzed in four replicates and the analytical results are summarized in Table 2 . The low values of the relative standard deviation (\%RSD) indicate the high precision and the good accuracy of the proposed methods ${ }^{24-26}$. RSD (\%) and SD values were obtained within the same

Table 3: Spectrophotometric determination of ESL and TRA drugs in different pharmaceutical preparations using $\mathrm{HIO}_{3}$ and $\mathrm{SA}_{\text {reagents and }}$ official method

\begin{tabular}{|c|c|c|c|c|c|c|}
\hline \multirow[b]{2}{*}{ Drug and dose } & \multicolumn{2}{|l|}{ Drug found } & \multicolumn{2}{|l|}{ Recovery (\%) } & \multirow[b]{2}{*}{$\mathrm{SD}^{\star}$} & \multirow[b]{2}{*}{$\mathrm{SD}^{\star \star}$} \\
\hline & Proposed method $\left(\mu \mathrm{g} \mathrm{mL}^{-1}\right)$ & Official method $\left(\mathrm{mg} \mathrm{mL}^{-1}\right)$ & Proposed method & Official method & & \\
\hline \multicolumn{7}{|l|}{ ESL } \\
\hline 100 & 101.0 & 99.0 & 101.00 & 99.00 & 0.06 & 0.05 \\
\hline 200 & 199.3 & 198.0 & 99.65 & 99.00 & 0.04 & 0.06 \\
\hline \multicolumn{7}{|l|}{ TRA } \\
\hline 100 & 99.0 & 102.0 & 99.00 & 102.02 & 0.04 & 0.05 \\
\hline 150 & 149.0 & 149.5 & 99.30 & 99.60 & 0.03 & 0.08 \\
\hline
\end{tabular}

«Standard deviation (SD) values using proposed method, $\star \star$ Standard deviation (SD) values using official method 
day to evaluate repeatability (intra-day precision) and over four days to evaluate intermediate precision (inter-day precision) $)^{24-26}$.

Limits Of Detection (LOD) and quantitation (LOQ): Sensitivity of the method can be determined, through the Limit of Detection (LOD) and Limit Of Quantification (LOQ). The LOD for the proposed method was calculated using the following equation ${ }^{27}$ :

$$
\mathrm{LOD}=3 \times \sigma / \mathrm{S}
$$

where, $\sigma$ is the standard deviation of replicate determination values and $\mathrm{S}$ is the slope of the calibration graph.

The LOQ defined $\mathrm{as}^{27}$ :

$$
\mathrm{LOQ}=10 \times \sigma / \mathrm{S}
$$

Based on the above equations, the limits of detection and quantification were calculated and recorded in Table 1.

Quantification: Under the specified reaction conditions, the molar absorptivity at $\lambda_{\max }$ was found to be a function of concentration of the investigated drug. Beer's law plots were linear with small intercept (0.0101-0.0277) and slopes (0.0012-0.0072) values in the concentration ranges were presented in Table 1 . The correlation coefficient, intercepts and regression equation for the proposed procedures were listed in Table $1^{28}$. The apparent molar absorptivities found to be in the order of $3.0 \times 10^{2}$ and $5.39 \times 10^{2} \mathrm{~L} \mathrm{~mol}^{-1} \mathrm{~cm}^{-1}$ with the Sandell sensitivities of 0.0126 and $0.0118 \mu \mathrm{g} \mathrm{cm}^{-2}$ for ESL and TRA drugs, respectively, as calculated from Beer's law (Table 1). The correlation coefficients of the data obtained are 0.9959 and 0.9989 for ESL and TRA drugs, respectively. Beer's law is obeyed over the concentration ranges from 5-500 and 2.5-275 $\mu \mathrm{g} \mathrm{mL}^{-1}$ for ESL and TRA drugs, respectively.

\section{CONCLUSION}

This study demonstrated that $\mathrm{HIO}_{3}$ and SA can be utilized as useful reagents for the spectrophotometric determination of ESL and TRA drugs, respectively, under investigation. Rapid formation of stable colour products is advantage of the suggested methods over the previously official titrimetric method. The proposed spectrophotometric methods are simpler, time saving and they involve very simple procedures, that can be applied in routine analysis.

\section{REFERENCES}

1. Takada, A., H. Ohashi, H. Matsuda and Y. Takada, 1979. Effects of tranexamic acid, CIS-AMCHA and 6-aminohexanoic acid on the activation rate of plasminogen by urokinase in the presence of clot. Thromb. Res., 14: 915-923.

2. Cederholm-Williams, S.A. and A. Swain, 1979. The effect of fibrinogen degradation products and some lysine analogues on the dissociation of plasmin(ogen)-fibrin complexes. Thromb. Res., 16: 705-713.

3. Sweetman, S.C., 2007. Martindale the Complete Drug Reference. Pharmaceutical Press, London, UK., Pages: 959.

4. Kaul, N., H. Agrawal, A. Kakad, S.R. Dhaneshwar and B. Patil, 2005. Stress degradation studies on etamsylate using stability-indicating chromatographic methods. Anal. Chim. Acta, 536: 49-70.

5. Nagaraju, P., K. Krishnachaithanya, V.D.N. Srinivas and S.V.N. Padma, 2008. Reverse phase high performance liquid chromatographic method for the determination of etamsylate in bulk and tablet dosage forms. Asian J. Res. Chem., 1: 88-90.

6. Jaiswal, Y., G. Talele and S. Surana, 2007. Application of HPLC for the simultaneous determination of ethamsylate and mefenamic acid in bulk drugs and tablets. J. Liquid Chromatogr. Relat. Technol., 30: 1115-1124.

7. Jaiswal, Y.S., G. Talele and S. Surana, 2005. A simple and sensitive HPTLC method for quantitative analysis of etamsylate in tablets. J. Plan. Chromatogr. Mod., 105: 380-383.

8. Jaiswal, Y.S., G.S. Talele and S.J. Surana, 2005. Quantitative analysis of ethamsylate and mefenamic acid in tablets by use of planar chromatography. JPC. J. Plan. Chromatogr. Mod. TLC, 18: 460-464.

9. Hassan, S.S.M., M.R. El-Bahnasawy and N.M. Rizk, 1997. Membrane sensors for batch and flow injection potentiometric determination of ethamsylate (cyclonamine) in pharmaceutical preparations. Microchim. Acta, 126: 217-222.

10. Zhang, C., J. Huang, M. Feng and Z. Zhang, 1998. Flow injection chemiluminescence determination of etamsylate with electrogenerated hypochlorite. Anal. Lett., 31: 1917-1928.

11. Yang, F., C. Zhang, W.R.G. Baeyens and X. Zhang, 2002. Determination of ethamsylate in pharmaceutical preparations based on an auto-oxidation chemiluminescence reaction. J. Pharmaceut. Biomed. Anal., 30: 473-478. 
12. Du, J., Y. Li, Y. Tang and J. Lu, 2002. Flow injection chemiluminescence determination of ethamsylate based on permanganate oxidation. Anal. Lett., 35: 463-472.

13. Garg, G., S. Saraf and S. Saraf, 2007. Simultaneous estimation of mefenamic acid and ethamsylate in tablets. Indian J. Pharm. Sci., 69: 279-281.

14. Goyal, A. and I. Singhvi, 2008. Spectrophotometric estimation of ethamsylate and mefenamic acid from a binary mixture by dual wavelength and simultaneous equation methods. Indian $\mathrm{J}$. Pharmaceut. Sci., 70: 108-111.

15. Vinay, K.B., H.D. Revanasiddappa,Z.D. Okram and K. Basavaiah, 2009. Permanganometric determination of etamsylate in bulk drug and in tablets. Chem. Ind. Chem. Eng. Q., 15: 149-157.

16. Shih, Y., K.L. Wu, J.W. Sue, A.S. Kumar and J.M. Zen, 2008. Determination of tranexamic acid in cosmetic products by high-performance liquid chromatography coupled with barrel plating nickel electrode. J. Pharmaceut. Biomed. Anal., 48: 1446-1450.

17. Chang, Q., O.Q.P. Yin and M.S.S. Chow, 2004. Liquid chromatography-tandem mass spectrometry method for the determination of tranexamic acid in human plasma. J. Chromatogr. B, 805: 275-280.

18. Sato, K., Y. Tobita, K. Iwabuchi and S. Tanaka, 1997. Determination of tranexamic acid and vitamins by high performance liquid chromatography with peroxyoxalate chemiluminescence detection. Anal. Sci., 13: 471-474.

19. Arayne, M.S., N. Sultana, F.A. Siddiqui, A.Z. Mirza and M.H. Zuberi, 2008. Spectrophotometric techniques to determine tranexamic acid: Kinetic studies using ninhydrin and direct measuring using ferric chloride. J. Mol. Structure, 891: 475-480.

20. Huertas-Perez, J.F., M. Heger, H. Dekker, H. Krabbe, J. Lankelma and F. Ariese, 2007. Simple, rapid and sensitive liquid chromatographyfluorescence method for the quantification of tranexamic acid in blood. J. Chromatogr. A, 1157: 142-150.
21. Rizk, M.S., S.S. Toubar, M.A. Sultan and S.H. Assaad, 2003. Ultraviolet spectrophotometric determination of primary amine-containing drugs via their charge-transfer complexes with tetracyanoethylene. Microchimica Acta, 143: 281-285.

22. Atmaca, S., 1989. Spectrophotometric determination of tranexamic acid with 2, 4, 6-trinitrobenzosulfonic acid. Acta Pharm. Turcica, 31: 115-118.

23. Takeuchi, T., Y. Kabasawa, R. Horikawa and T. Tanimura, 1988. Flow injection determination of drugs by specific detection of carboxylic acids. Analyst, 113: 1673-1675.

24. Frag, E.Y., G.G. Mohamed and M.H. Gaber, 2011. Sensitive extractive spectrophotometric method for the determination of some statin drugs in pharmaceutical preparations. Insight Pharmaceut. Sci., 1: 39-46.

25. Frag, E.Y., G.G. Mohamed, A.B. Farag and E.B. Yussof, 2011. Utility of $\pi$ and $\sigma$-acceptor reagents for the spectrophotometric determination of cefotaxime sodium antibacterial drug via charge transfer complex formation. Insight Pharmaceut. Sci., 1: 47-54.

26. Frag, E.Y., Z.A.B. Farag, G.G. Mohamed and E.B. Yussof, 2012. Development and validation of spectrophotometric and hplc methods for the determination of cefixime in capsule and suspension. Insight Pharmaceut. Sci., 2: 8-16.

27. Basavaiah, K. and S.A.M. Abdulrahman, 2010. Use of charge transfer complexation reaction for the spectrophotometric determination of bupropion in pharmaceuticals and spiked human urine. Thai J. Pharm. Sci., 34: 134-145.

28. Saleh, G.A., H.F. Askal, M.F. Radwan and M.A. Omar, 2001. Use of charge-transfer complexation in the spectrophotometric analysis of certain cephalosporins. Talanta, 54: 1205-1215. 